\title{
EVALUATION OF THE GNSS POSITIONING PERFORMANCE UNDER INFLUENCE OF THE IONOSPHERIC SCINTILLATION
}

\author{
Mayara Cobacho Ortega Caldeira ${ }^{1}$ - ORCID: 0000-0002-2427-9363 \\ Carlos Rodrigo Tanajura Caldeira ${ }^{1}$ - ORCID: 0000-0001-7102-7735 \\ Samara Sunny dos Anjos Cereja² - ORCID: 0000-0003-4721-8464 \\ Daniele Barroca Marra Alves ${ }^{3}$ - ORCID: 0000-0002-9033-8499 \\ Claudinei Rodrigues de Aguiar ${ }^{4}$ - ORCID: 0000-0002-6402-4234 \\ ${ }^{1}$ Universidade Federal Rural da Amazônia - UFRA, Instituto Ciberespacial, Belém - Pará, Brasil. \\ E-mail: mayara.caldeira@ufra.com.br; carlos.caldeira@ufra.edu.br
${ }^{2}$ Universidade Federal Rural da Amazônia - UFRA, Curso de Engenharia Cartográfica e de Agrimensura, Belém - Pará, Brasil. \\ E-mail: samarasunny@yahoo.com.br \\ ${ }^{3}$ Universidade Estatual Paulista - UNESP, Departamento de Cartografia, Presidente Prudente - São Paulo, Brasil. \\ E-mail: daniele.barroca@unesp.br \\ ${ }^{4}$ Universidade Tecnológica Federal do Paraná - UTFPR, Coordenação de Engenharia Civil, Apucarana - Paraná, Brasil. \\ E-mail: rodrigues.aguiar@gmail.com
}

Received in $24^{\text {th }}$ April 2020

Accepted in $22^{\text {nd }}$ August 2020

\begin{abstract}
:
The ionosphere may not only degrade the accuracy of the GNSS positioning but also reduce its availability because there is a high dependence between signal losses and ionospheric irregularities. Irregularities in the Earth's ionosphere may produce rapid fluctuations in phase and amplitude. These rapid fluctuations are called ionospheric scintillation. Thus, loss of signal can occur due to the effects of diffraction and refraction, which cause a weakening in the signal received by the GNSS receivers. In this way, this paper aims to evaluate the magnitude of ionospheric scintillation in Brazil and the performance of the positioning under its influence in the period of high solar activity in the current cycle (24), through the Spearman correlation analysis and the Wavelet periodogram. For that, three-year time series (2012 to 2014) of the S4 index and 3D MSE (Mean Squared Error) of three Brazilian stations with different ionospheric conditions were considered, PALM (near the Geomagnetic Equator) PRU2 (Equatorial region and Anomalies) and POAL (Mid-latitude region). Thus, it was possible to evaluate the correlation between the accuracy of the precise point positioning using only the C/A code of the GPS satellite and the S4 index. As a result, there was a correlation of $53 \%$ and $51 \%$, using the Spearman method, for the PALM and PRU2 series, respectively. In addition, considering the analysis of space-frequency in relation to time by the Wavelet coherence method, a correlation of more than $70 \%$ is noted in the period of greatest 3D MSE concerning the spring and autumn equinox months.
\end{abstract}

Keywords: Ionospheric Effects; Correlation; Wavelet Coherence; S4 Index.

How to cite this article: CALDEIRA, M. C. O.; CALDEIRA, C. R. T.; CEREJA S. S. A.; ALVES, D. B. M.; AGUIAR, C. R. Evaluation of the GNSS positioning performance under influence of the ionospheric scintillation. Bulletin of Geodetic Sciences. 26(3): e2020014, 2020. 


\section{Introduction}

Nowadays, space technologies have been widely employed, among them one of the main and most modern ones is the GNSS (Global Navigation Satellite System). Among the various positioning systems that integrate the GNSS, the one that still stands out the most is the North American GPS (Global Positioning System), although the Russian constellation, GLONASS (Global Orbiting Navigation Satellite System), is already complete. The European (Galileo) and Chinese (Beidou) systems, have been launching satellites to make the system operational (Monico, 2008; Montenbruck et al., 2017).

However, the data transmitted by the GNSS systems are subject to error, either due to the satellites themselves that compose the constellations, as well as the signal propagation, receiver and the station. Most of these errors can be eliminated, reduced, or modeled. This depends a lot on the positioning method used and on desired accuracy (Monico, 2008; Seeber, 2003). The ionosphere became the main source of systematic error in GNSS positioning for single frequency receivers, after the deactivation of the SA (Selective Availability) technique on May 2, 2000 (Monico, 2008; Matsuoka, 2007; Seeber, 2003).

The magnitude of the error due to the ionospheric effect on the GNSS signals depends directly on the Total Electron Content (TEC) present along the path traveled by the signal, which in turn is related to the ionization process in the ionosphere, and inversely proportional to the squared signal frequency (Matsuoka, 2007; Camargo, 1999; Pereira and Camargo, 2017). TEC and, consequently, the ionospheric error vary in time and space, and are subject to several influences (Davies, 1990). Besides, the ionosphere can not only degrade the accuracy of GNSS positioning but also reduce its availability, as there is a high dependence between signal losses and ionospheric irregularities (Kintner et al., 2007).

Irregularities in the Earth's ionosphere may produce short-period variations in signals, caused by rapid fluctuations in phase and amplitude, due to the effects of diffraction and refraction, that cause a weakening in the signal received by the GNSS receivers (Conker et al., 2003; Vani et., 2019). These rapid fluctuations are called ionospheric scintillation (De Paula et al., 2008; Conker et al., 2003; Kintner et al., 2007; Abdu et al, 2014).

Studies conducted by Muella et al. (2013) and Jiao and Morton (2015), indicate that in equatorial/low latitudes the occurrence of scintillation is predominant during the months of the equinox and is mainly a phenomenon after sunset. Strong scintillation is capable of leading to loss of tracking and satellite signal degradation, especially for the phase (Sreeja et al., 2012), which is crucial for professional applications of high precision in real time. In Brazil, for example, more than $90 \%$ of precision agriculture is severely affected, especially after solar sunset (Pereira et al., 2018).

Another important aspect is that during the maximum solar activity and for satellites near the horizon, the error can be greater than $100 \mathrm{~m}$, due to the reduction in the modulation speed emitted by the GPS satellites (Leick, 1995). In Salomoni et al. (2009) and Souza, Alves and Vani (2015), the results show the difference in the error obtained in the positioning in periods of high solar activity and low solar activity, where it is possible to see the influence of the solar cycle on the quality of the data obtained in the positioning. According to studies carried out by Skone, Knudsen and De Jong (2001) in periods of high solar activity, the L2 signal is strongly affected due to ionospheric scintillation, and its data is corrupted by up to $40 \%$.

Analyzing the data during the peak period of solar cycle 23, Skone and Shrestha (2002) reported that the degradation in the horizontal and vertical positioning close to the equatorial anomaly led to errors of 25-30 $\mathrm{m}$ for the DGPS (Differential GPS) positioning during the equinoctial months for Brazilian regions. Dal Poz, Camargo and Aguiar (2008), report that in the period of maximum solar activity, the planimetric and altimetric discrepancies reached $25 \mathrm{~m}$ in the long baseline relative positioning. From an investigation with Odds Ratio and Fisher's exact tests, Alves, Souza and Gouveia (2020) found that the chance of large discrepancies in the 3D positioning coordinates can be three times greater under strong scintillation effects than under moderates, in the period of maximum solar activity of cycle 24. 
The high ionospheric activity intensifies the effect of the electrojet on the geomagnetic equator, increasing the magnitude of the Equatorial Ionization Anomaly (EIA), as well as amplifying the ionospheric irregularities (Davies, 1990; Aguiar, 2010; Mendonça, 2013; Ram, Su and Liu, 2009, Muella et al., 2013). The effects are more severe in the equatorial/low latitudes, where the occurrence of scintillation is associated with the ridges of the EIA, delimited by $15^{\circ}$ to the north and south of the geomagnetic equator (Basu et al., 2002). Brazil has a large part of its territory located in the equatorial and low latitudes regions, strongly affected by this effect and by the Equatorial Plasma Bubbles (EPB - Barros et al., 2018) (Moraes et al., 2018).

The effects of ionospheric scintillation on positioning have been reported over decades in the literature, such as Groves et al. (2000), Dubey et al. (2006), Aquino et al. (2009), Park et al. (2017), Moreno et al. (2011), Luo et al. (2018), Marques et al. (2018), Veettil et al. (2020), among others, point out that GNSS positioning errors can increase significantly in magnitude under conditions of intense scintillation. However, in this literature, in general, punctual intervals of data are analyzed, daily to monthly, emphasizing, mainly on the daily impact, i. e., they do not show the behavior in an annual time series or of a long period of data.

In this way, this research evaluates the magnitude of the ionospheric amplitude scintillation in Brazil and the positioning performance under its influence, contemplating three years of data in the period of high solar activity of cycle 24. For this, the Precise Point Positioning (PPP) was performed using only the C/A code over the years from 2012 to 2014. The investigation of the correlation between the accuracy of the PPP and the occurrence of ionospheric scintillation was based on the statistics of the Mean Squared Error (MSE) of the positioning and magnitude of the values of the S4 index observed in the PALM (close to the Geomagnetic Equator), PRU2 (low latitudes region and EIA) and POAL (Mid-latitudes region) stations belonging to the CIGALA (Concept for lonospheric Scintillation Mitigation for Professional GNSS in Latin America) and the CALIBRA project (Countering GNSS high Accuracy applications Limitations due to lonospheric disturbances in Brazil).

Furthermore, in order to analyze the seasonal variation as verified by Muella et al. (2013), Skone and Shrestha (2002), Ji et al. (2013), in this research was used the technique of the periodogram of the Wavelet coherence, since it relates space-frequency to time. It is worth mentioning that, although this technique is applied in several researches to the study of the correlation of scintillation (Fernández, Meza and Van Zele, 2013; Ahmed et al., 2015; Brassarote, Souza and Monico, 2018), it is usually adopted for daily analysis or short intervals of time. Thus, the proposal is to validate this methodology using a times series of three years corresponding to the maximum solar activity, as the effects in this period are enhanced.

\section{2. lonosphere and its effects on positioning}

The solar radiation causes the photoionization of the Earth's atmosphere at high altitudes, creating, in the upper atmosphere, regions with a high density of free electrons. This region is the ionosphere layer, which lies approximately between 50 and 1000 above the Earth's physical surface (Davies,1990; McNamara,1991). The ionosphere affects the propagation of radio waves, such as those transmitted by GNSS satellites.

The ionosphere behaves as a dispersive medium for the GNSS frequency bands, affects the modulation and the carrier phase, causing them to experience, respectively, a delay and an advance. The magnitude of the error due to the ionosphere on the GNSS signals depends directly on the TEC present along the path traveled by the signal (Monico, 2008). Thus, TEC is the main descriptor parameter of the ionospheric effect on GNSS signals, however, it varies in time and space.

Temporal variations, such as diurnal variations (due to solar radiation related to Local Time), seasonal variations (due to alteration of the solar zenith angle, as well as the intensity of the ionization flux, being that in the southern hemisphere, the ionospheric effects are higher in the months of equinox and in the months of solstices are 
smaller) and cycles of long periods, directly influence the variation of electron density in the ionosphere (McNamara, 1991; Monico, 2008; Matsuoka, 2007). Regarding variations in long-term cycles lasting approximately 11 years, the occurrence of sunspots is associated, and the increase in ionization is proportional to the number of spots (Figure 1).

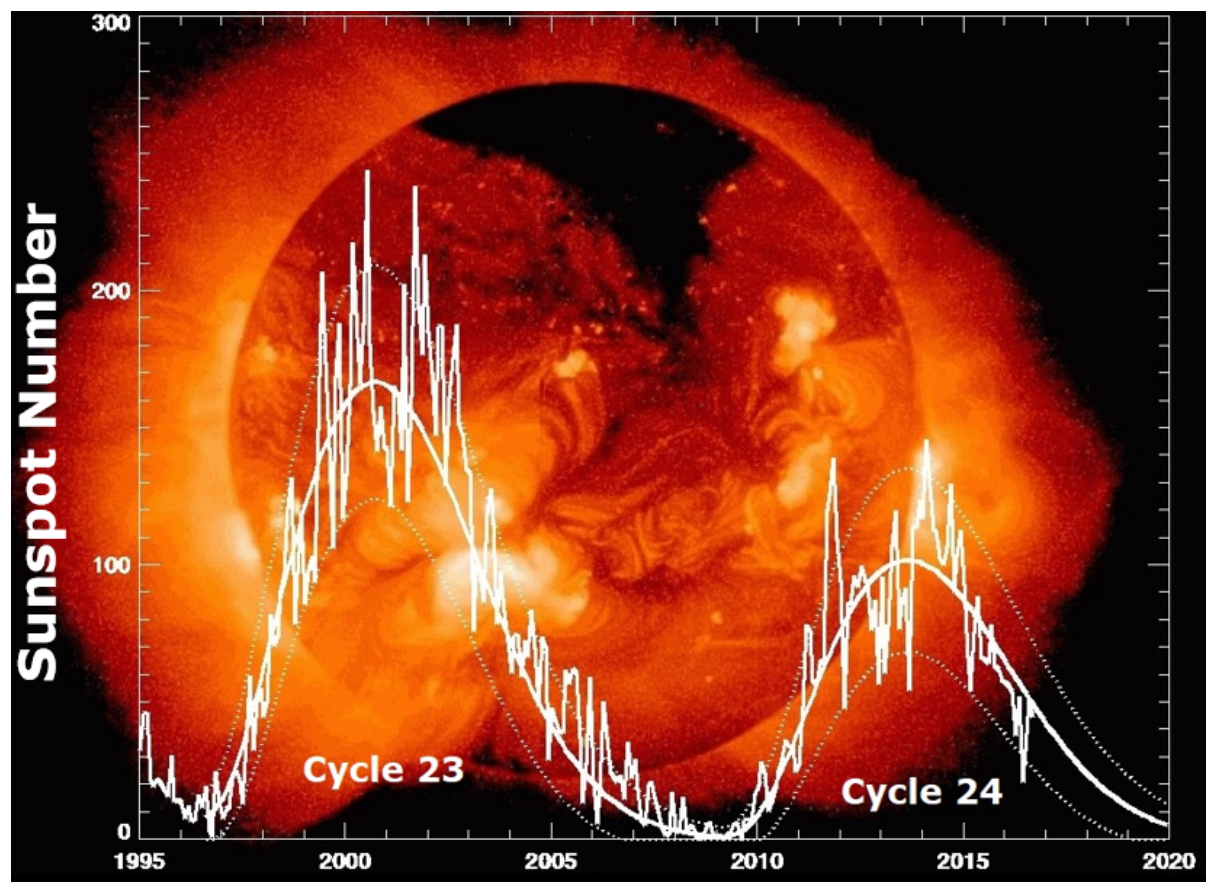

Source: NASA, 2019.

Figure 1: Number of sunspots in Cycle 24

Currently (2020), the Sun is at the end of the so-called "Cycle 24", and the period of maximum solar activity was between the years 2013 and 2014, which caused an increase in the number of sunspots, and consequently, in the number of electrons in the ionosphere. Figure 2 shows the occurrences from the years 2012 to 2014, highlighting the two peaks of greater magnitude in the months of the equinox.

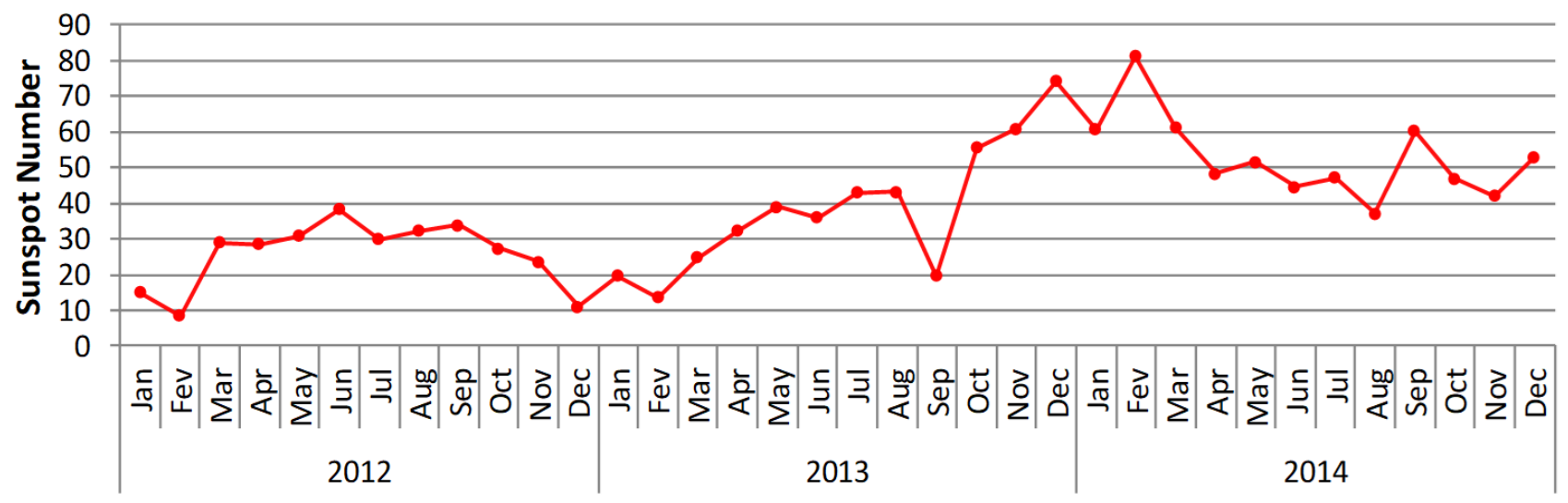

Figure 2: Occurrence of sunspots from 2012 to 2014 (Monthly average)

In addition, there is a strong influence of solar events on Earth, such as Coronal Mass Ejections and Solar Flares, because depending on the intensity and magnitude of these events, it causes the Earth to be constantly "bombarded" by hot, magnetized and supersonic plasma, with a considerable amount of kinetic and electrical energy and capacity to conduct current (Ruviaro, Matsuoka and Camargo, 2012; Fedrizzi, 2003). The effect 
caused by this bombardment is the change of the characteristics of the normal magnetic field (McNamara, 1991; Moldwin, 2008; Kelley, 2006).

The global structure of the ionosphere is not homogeneous. It changes with latitude, due to the variation of the solar zenith angle, which directly influences the level of solar radiation, and consequently changes the density of electron. Figure 3 shows the location of the three largest geographic regions of the ionosphere: Equatorial, Mid-latitudes and Polar. Equatorial regions delimited approximately by geomagnetic latitudes $20^{\circ} \mathrm{S}$ and $20^{\circ} \mathrm{N}$ are characterized by a high level of electron density. On the other hand, the regions of midium latitudes, delimited between the latitude of $\pm 20^{\circ}$ to $\pm 60^{\circ}$, are considered relatively free of ionospheric anomalies, while the polar regions, delimited between the latitude of $\pm 60^{\circ}$ to $\pm 90^{\circ}$, are not very predictable (Webster, 1993).

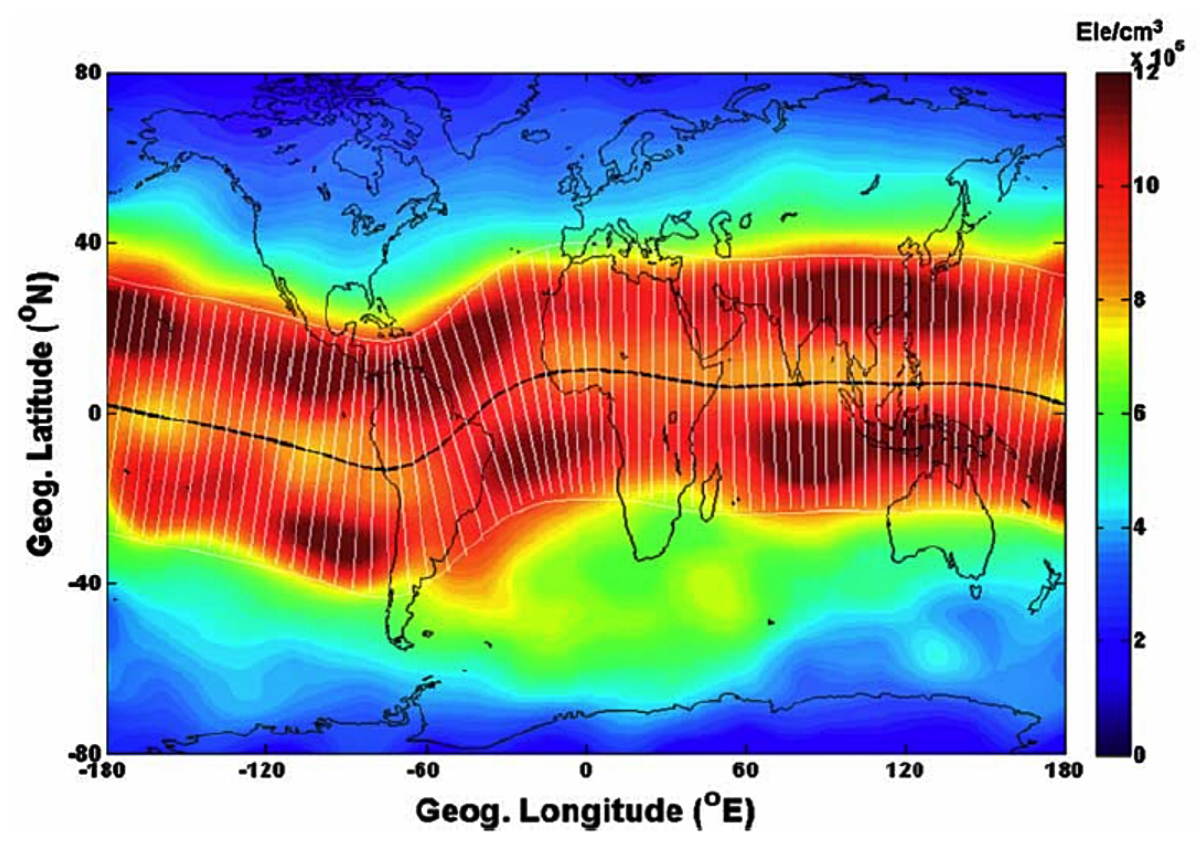

Source: Ram, Su and Liu (2009)

Figure 3: Geographical Regions of the lonosphere

Due to the high solar radiation in the equatorial region and the Earth's magnetic and eletric fields, the density of electrons in the ionosphere in this region suffers irregularities (Mc Namara, 1991; Oliveira, 2003). After the rise of the plasma to high altitudes in the equatorial region, the plasma begins a downward movement along the lines of the geomagnetic field, due to the action of gravity and pressure-gradient force. This phenomenon of plasma elevation in the equatorial region and subsequent descent along magnetic field lines to low latitudes is known as the Fountain Effect (Rishbeth e Garriott, 1969; Ram, Su and Liu, 2009; Luo et al., 2018).

A consequence of the combination of these movements, leads to an increase in ionization in regions close to \pm $15^{\circ}$ of magnetic latitude, being that in the geomagnetic equator it is less intense (Basu et al., 2002, Moraes et al., 2018). Such enhancements are commonly referred to as the northern and southern crest of the Equatorial Ionization Anomaly (EIA), respectively (Cesaroni et al., 2015; Moreno et al., 2011). Rayleigh-Taylor instability, caused by the formation of ridges, allows the formation of low ionization spots, known as lonospheric Plasma Bubbles (IPBs) or Equatorial Plasma Bubbles (EPB), whenn some force, for example, gravity waves are present (Barros et al, 2018; Abdu et al., 2013), that are huge regions of space where the density of ionospheric plasma is drastically reduced (Webster, 1993).

Irregularities in the Earth's ionosphere may produce short-period variations in signals, caused by rapid fluctuations in phase and amplitude, due to the effects of diffraction and refraction (Matsuoka, 2007; Conker et al., 2003; Davies, 1990). 
These rapid fluctuations are called ionospheric scintillation and, normally, the irregularities that cause scintillation are located between 200 and $600 \mathrm{~km}$ of altitude (peak altitude of region F) (De Paula et al., 2008; Conker et al., 2003; Abdu at al. 2013). The scintillation can cause degradation in GNSS measurements and, in the worst case, can lead to a loss of blocking signal to the satellite, affecting service and availability and potentially leading to interruptions that can last from minutes to hours (Vani et., 2019). According to Davies (1990), a radio signal that crosses the ionosphere will be modified by irregularities ranging in size from a few meters to kilometers, which can become a severe problem to the point of making the tracking signal unfeasible.

Irregularities in small scale embedded in IPBs and EPBs are the main sources for the phenomenon of scintillation in low latitude (De Paula et al., 2008, Cesaroni et al., 2015). Since the last few decades, several studies have reported that equatorial scintillations are mainly evening events, occurring in particular during after sunset (Sahai, Fagundes and Bitencourt, 2000; Cesaroni et al., 2015; Muella et al., 2013). Considering the morphology of the Earth's magnetic field, the geographic regions where scintillations are most likely to occur are the polar and equatorial areas, exacerbating in the low latitude regions (Kintner et al., 2007).

Estimations of ionospheric scintillation can be defined in terms of the spectral density of the signal power (Power Spectral Density - PSD) (Conker et al., 2003). Specific indices can also be produced, which denote factors of intensity of ionospheric scintillation. Two indices are more prominent in the literature: the $\mathbf{S 4}$ index, for amplitude scintillations, and the Sigma- $\phi(\sigma \phi)$ index, for phase scintillations.

The index adopted for analysis was amplitude, the S4. This index is adimensional and some thresholds for its values can be found in the literature. Conker et al. (2003) define that a value of 0 indicates the absence of scintillation, while a value of 1 indicates severe scintillation. Tiwari et al. (2011) presents three levels of classification for the index mentioned, Strong Scintillation: S4 $\geq 1$; Moderate Scintillation: $0.5<$ S4 < 1; Weak Scintillation: S4 $\leq .5$.

During the scintillation events, L1 tracking performance is less affected than L2 tracking. The signal loss in L2 strongly affects applications where dual frequency observations are required. However, according to the results of the kinematic PPP of the Marques, Monico and Marques (2016) using L2C codes instead of P2 codes show precision improvement of up to $33 \%$ in periods of weak or strong ionospheric scintillation, and an improvement in accuracy up to $59 \%$ by combining the phase and the code collected under weak scintillation effects.

These applications depend, therefore, on the dispersive nature of the ionosphere, and consequently, it becomes necessary to monitor ionospheric scintillations. However, the performance of the tracking of GNSS receivers depends not only of the activity of ionospheric scintillation, but also on the capacity to track these receivers (Skone, 2000; Conker et al., 2003).

In Brazil, the monitoring and generation os maps in real-time of ionospheris scintillation and TEC is performed by INPE (National Institute for Space Research) through the SCINTEC system. A daily diagnosis of the ionosphere over the Brazilian territory is carried out by INPE's Brazilian Space Weather Study and Monitoring Program (EMBRACE).

Another initiative to study/model the effects of ionospheric scintillation on GNSS positioning is the project called CIGALA/CALIBRA and the MImOSA project (Monitoring the lonosphere Over South America). These projects aim to analyze the effects of scintillation, understand its causes and develop new techniques to be implemented in GNSS receivers, which involve members from several institutions in Europe and Brazil, which includes FCT/Unesp. Regarding the CIGALA/CALIBRA Project, the ISMR Query Tool was delevoped (Vani, Shimabukuro e Monico, 2017), which allows queries and analyzes on these data.

Various research on ionospheric mitigation has been developed in the last years, such as: Pereira and Camargo (2017), Alfonsi et al. (2017), Park et al. (2017), Muella et al. (2017), Vani et al. (2019), Veettil et al. (2020), Materassi et al. (2020), among others. 


\section{Materials and Methods}

\subsection{Dataset}

For correlation analyzes, data from reference stations belonging to the CIGALA/CALIBRA Network were used: PRU2, PALM and POAL (Figure 4). The first being located in a region that suffers a great influence of the ionospheric scintillation, since it is located close to the geomagnetic latitude $22^{\circ} \mathrm{S}$, region that suffers major ionospheric effects, such as EPB and EIA. In what concerns the second (PALM), it is a station that is spatially related to the electron elevation of the fountain effect, i.e., close to the geomagnetic equator, suffering less influence from the ionosphere. The last station (POAL) is located in a region that is considered relatively free of ionospheric effect, the region of medium latitudes.

In this way, in order to evaluate the impact of ionospheric scintillation on GNSS positioning, data from the entire year of 2012 (high sunspots), 2013 and 2014 (peak of the solar cycle 24) for these stations were selected. In total, 934 days of data for the PRU2 station, 782 days for PALM station and 660 days for POAL station. It is noted that this difference is due to the non-availability of the Receiver Independent Exchange Format (RINEX) file of the CIGALA/CALIBRA network and/or scintillation information on the ISMR Query Tool platform.

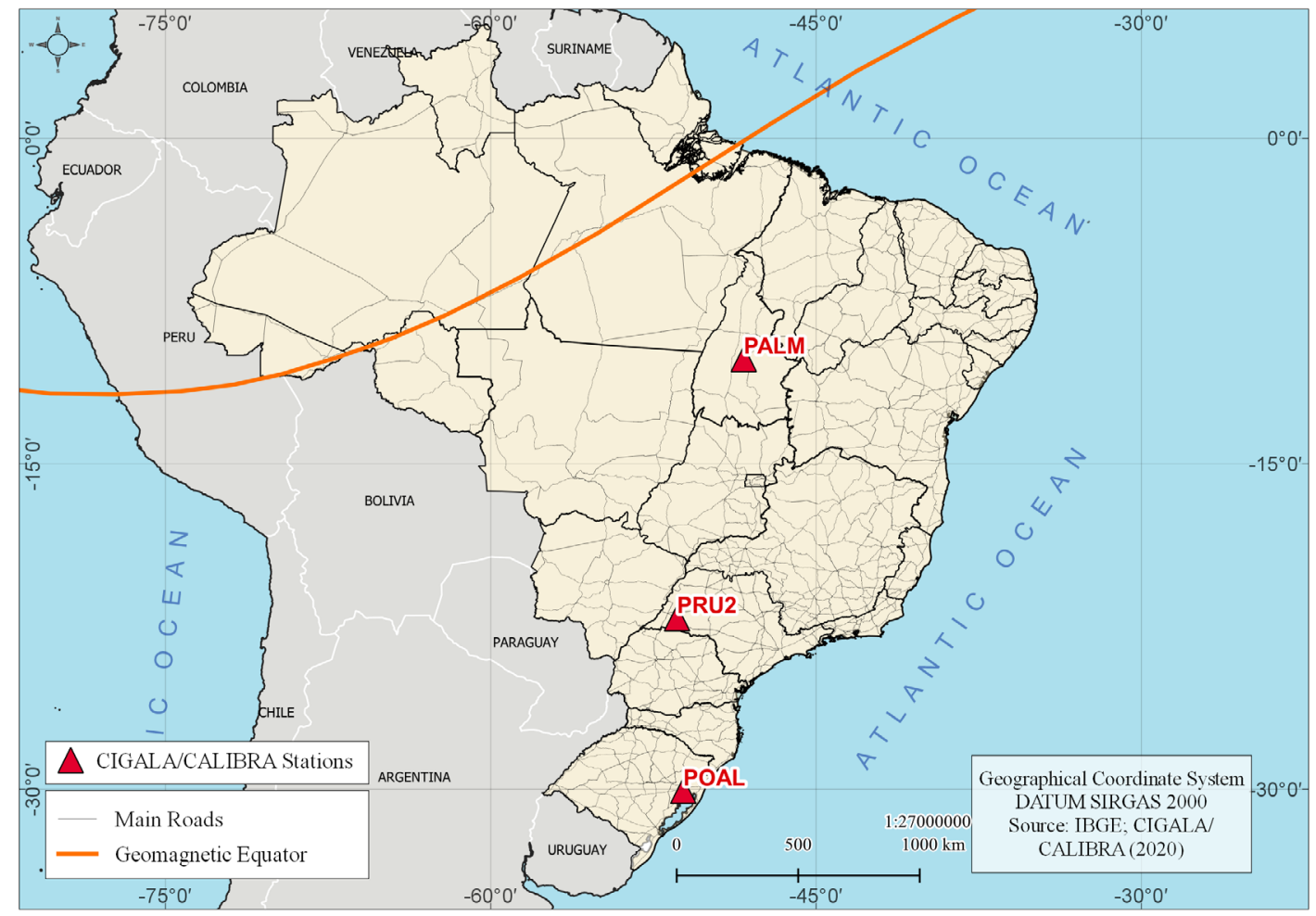

Source: Adapted from http://is-cigala-calibra.fct.unesp.br/is/stations/fixed.php

Figure 4: Location of the PRU2, PALM and POAL station CIGALA/CALIBRA Network

Thus, it was also possible to evaluate the influence of the peak on the positioning. It is necessary to emphasize that the high ionospheric activity should intensify the effect of the electrojet on the geomagnetic equator, increasing the magnitude of the equatorial anomaly, as well as amplifying the ionospheric irregularities, among them the ionospheric scintillation. 
Therefore, S4 ionospheric scintillation rates higher than 0.5 were applied through a script that accesses the CIGALA/ CALIBRA project database using the ISMR Query Tool - Retrieval (Vani, Shimabukuro and Monico, 2017). The average daily scintillation index of the GPS satellites was also used, consistent with the values provided by the ISMR Query Tool Calendar View of the study stations. Subsequently, a script was developed in Gnuplot to plot the $S 4$ indexes.

\subsection{Methodology}

Regarding the positioning, the precise point positioning of the stations was performed for the same period, whose data were automatically downloaded from the CIGALA/CALIBRA database through a script. Subsequently, three scripts developed in PHP (Hypertext Preprocessor) were also used, first one to remove L1, L2 and P2 observables from GPS satellite RINEX files using TEQC toolkit (UNAVCO, 2014). Another script to process the data in the free online service to post-process of the CRSR-PPP (Canadian Spatial Reference System) developed by the Natural Resources Canada's (NRCan) Geodetic Survey Division, in static mode using only the C/A code and final precise ephemeris. Finally, one to read the file with the results (discrepancy and standard deviation) of the processing (.SUM), so that from these it was possible to calculate the MSE (Mean Squared Error).

At first, visual analysis was performed associating the three-dimensional MSE series of the PPP with the scintillation index S4. However, for statistical analysis, it was essential the manipulation of the scintillation data extracted from the CIGALA/CALIBRA database, since it was necessary to relate only a single daily value concerning scintillation and 3D MSE. In this way, the daily weighted average of the index was used, including only satellites that had scintillation values greater than 0.5 (strong scintillation), where it was assigned to $0.5<S 4<0.7 ; 0.7<S 4<1$; S4>1, weights 1,2 or 3, respectively. For the analysis and calculation of the correlation, the mathematical and statistical software $R$ was used, employing the method available in its correlation package, Spearman, due to the asymmetry of the data.

Additionally, wavelet coherence color maps were analyzed, which is a technique based on the Continuous Wavelet Transform (Fernández, Meza and Van Zele, 2013; Ahmed et al., 2015; Brassarote, Souza and Monico, 2018) and allows to detect similarities and correlations between two temporal quantities. In this way, it was possible to analyze through this technique how the MSE and the scintillation index are correlated.

\section{Results and Discussion}

Figure 5 shows the average daily scintillation index for the year 2012-2014 for POAL (a), PALM (b) and PRU2 (c) stations, respectively. Note the influence of sunspots on the values of the scintillation index, with the values of greater magnitude concerning the peak of solar cycle 24, i.e., in 2014. This effect can be noticed when comparing the time series of the scintillation index of the three study stations presented. 

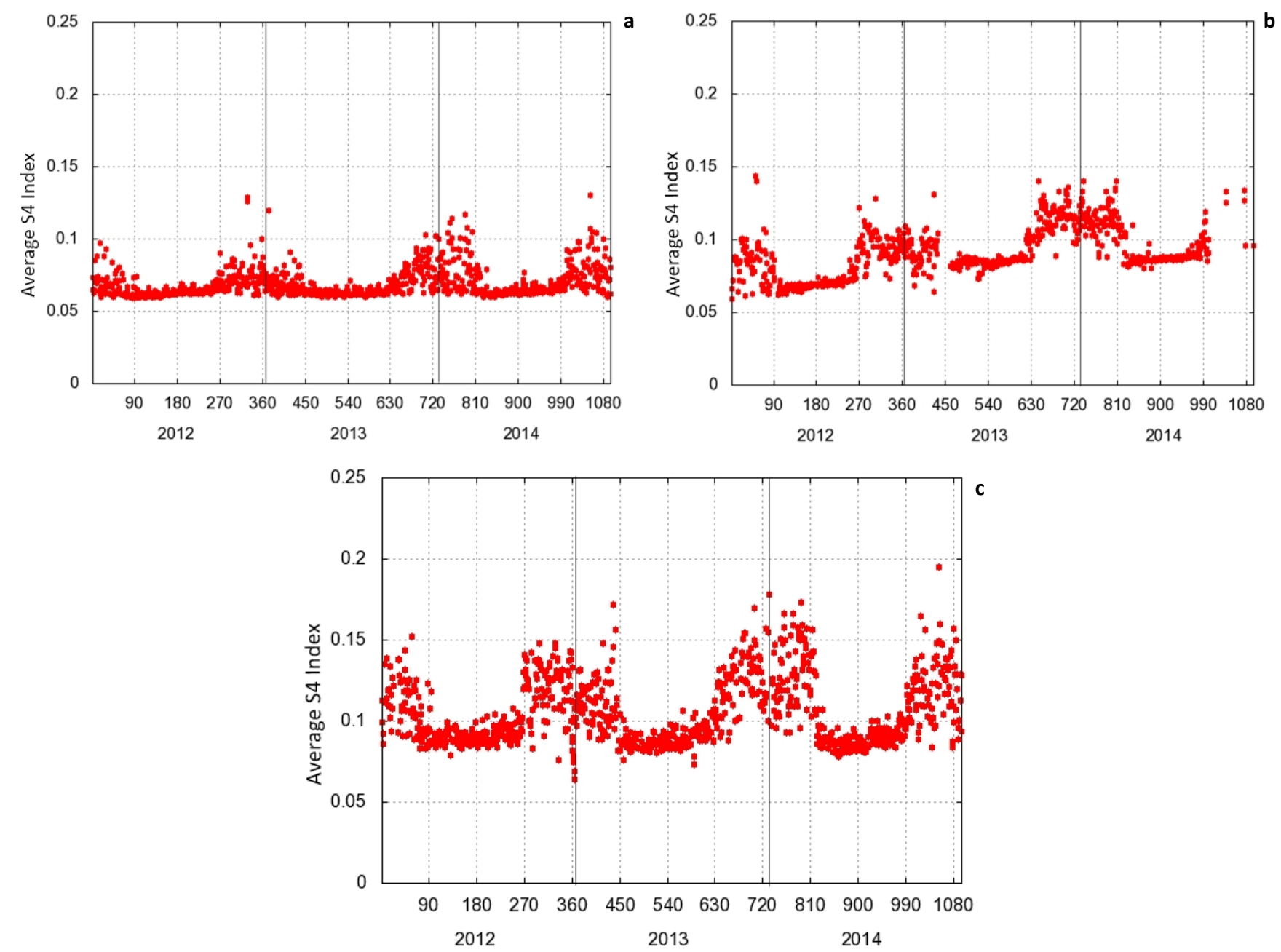

Figure 5: Average daily Scintilation Index S4 of the POAL (a), PALM (b), PRU2 (c) stations

Concerning the POAL station (Figure 5a), although located in a region of medium latitudes, i.e, with a lower ionospheric effect, in 2014 the average scintillation index increased by $6.4 \%$ compared to 2012. Likewise, the average S4 index in 2014 of the PALM (Figure 5b) and PRU2 (Figure 5c) stations achieved an increase of 17.0 and $6.7 \%$, respectively, in relation to the year of lower intensity of solar activity (2012).

However, the figures mentioned because it is the daily average of all satellites in the S4 index, these data may mask some analyzes. Therefore, are represented in the Figures 6 to 8 the weighted average scintillation index greater than 0.5 (S4>0.5), together with the daily results of the 3D MSE of PPP in the static mode from the years 2012 to 2014, from the POAL, PALM and PRU2 stations, respectively. In this way, it is possible to verify a possible visual correlation between the two quantities, based on the analysis of the trend lines of the series. 


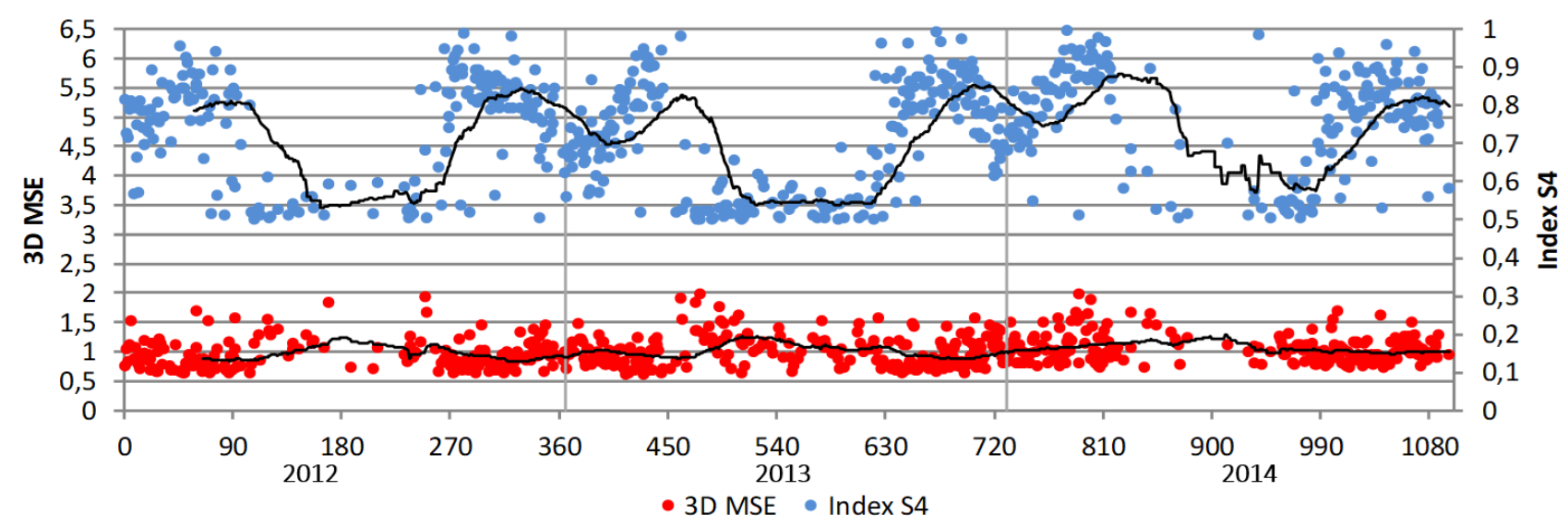

Figure 6: 3D MSE of Static PPP mode and average scintillation index S4 > 0.5 of POAL station

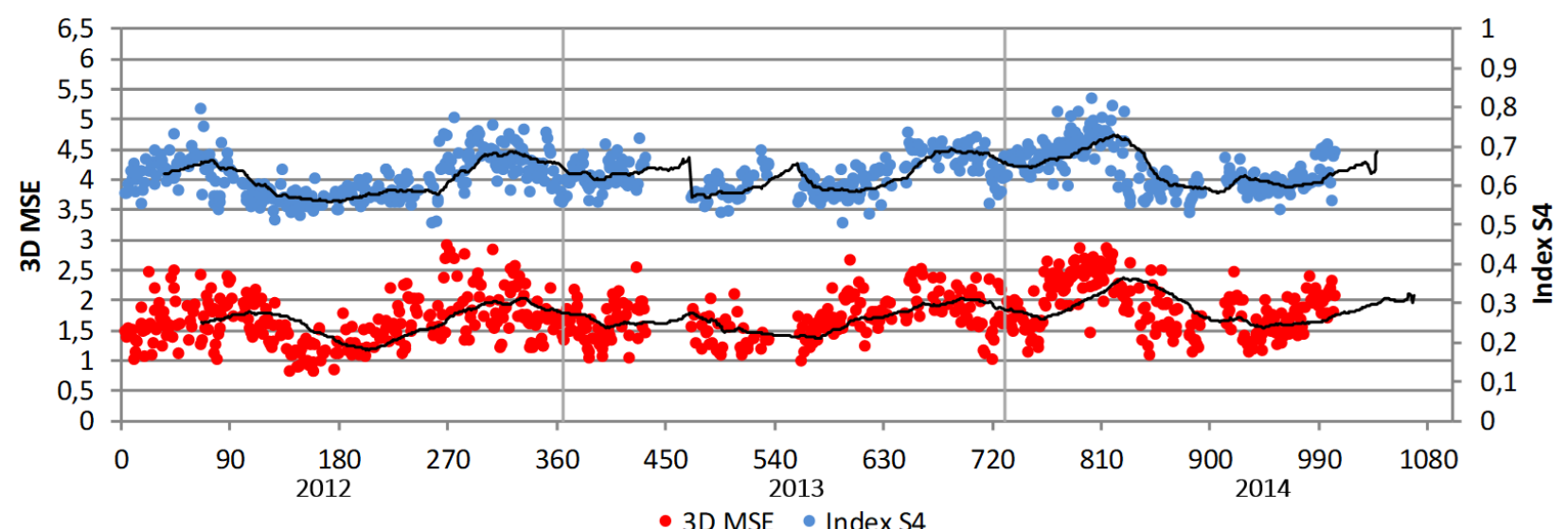

Figure 7: 3D MSE of Static PPP mode and average scintillation index S4 > 0.5 of PALM station

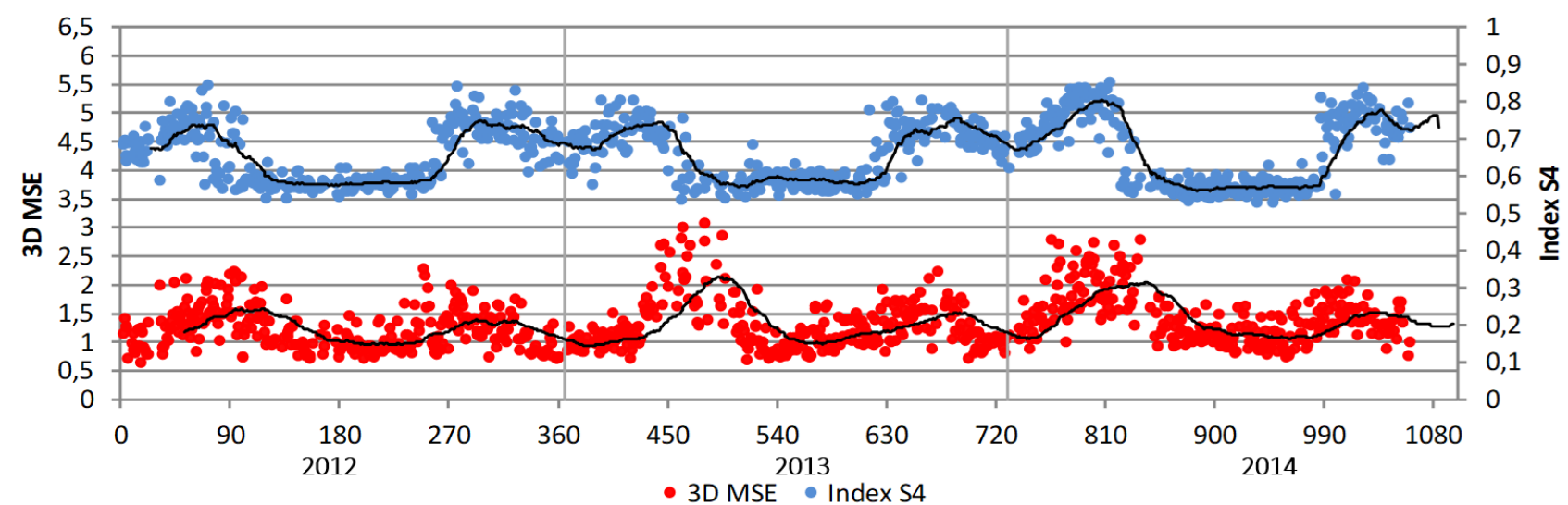

Figure 8: 3D MSE of Static PPP mode and average scintillation index $S 4>0.5$ of PRU2 station

As can be observed in Figure 6 to 8 , it is clear the influence of the seasonal variation of ionospheric scintillation on positioning for the PALM and PRU2 stations, especially when the time series trend line is verified. When relating the positioning error to the ionospheric scintillation S4 index, it is noted that in the period of intense ionospheric irregularities, which goes from the spring equinox (September - November) to the autumn equinox (March and April), these values are reduced around 3 times, obtaining an MSE around the meter or sub-meter.

However, this high graphical correlation does not match the numerical correlation obtained in the software 
R Spearman method, of 0.305 and 0.27 , for PALM and PRU2 station, and a 0.16 decorrelation for POAL station. Regarding the annual correlation of the PALM station, there is 0.36, 0.17 and 0.37 for 2012, 2013 and 2014 respectively. In the same way, it has $0.14,0.08$ and 0.27 for PRU2 station. Finally, there is a decorrelation of 0.21 , 0.22 and 0.04 , for POAL station. This low correlation presented, even employing the most appropriate method due to the asymmetry of the data, shows that the function employed is sensitive to small variations in the values concerning the 3D MSE and the S4 index, since mainly during the winter solstice period there are points out of the trend. Thus, the correlation was evaluated after excluding these points (Table 1).

Table 1: Correlation between 3D MSE of PPP and the S4 index

\begin{tabular}{ccccc}
\hline Station & 2012 Correlation & 2013 Correlation & 2014 Correlation & Triennial Correlation \\
\hline POAL & -0.32 & -0.34 & 0.05 & -0.21 \\
\hline PALM & 0.45 & 0.25 & 0.53 & 0.46 \\
\hline PRU2 & 0.29 & 0.15 & 0.51 & 0.31 \\
\hline
\end{tabular}

Based on the correlations shown in Table 1, the 2012 and 2014 time series of the PALM and PRU2 stations were evaluated using the Wavelet coherence technique, since these presented the highest correlations. Figures 9 and 10 show the Wavelet coherence color maps of the 2012(a) and 2014(b) series for the PRU2 and PALM stations, respectively, with the largest correlations being represented by warm colors, as the cold colors are concerning low correlation. It is worth mentioning that the maximum correlation of the three series of the stations occurred at the peak of solar activity in the cycle 24,2014 , where such fact directly influences the ionized particles, as well as intensifies the ionospheric irregularities.

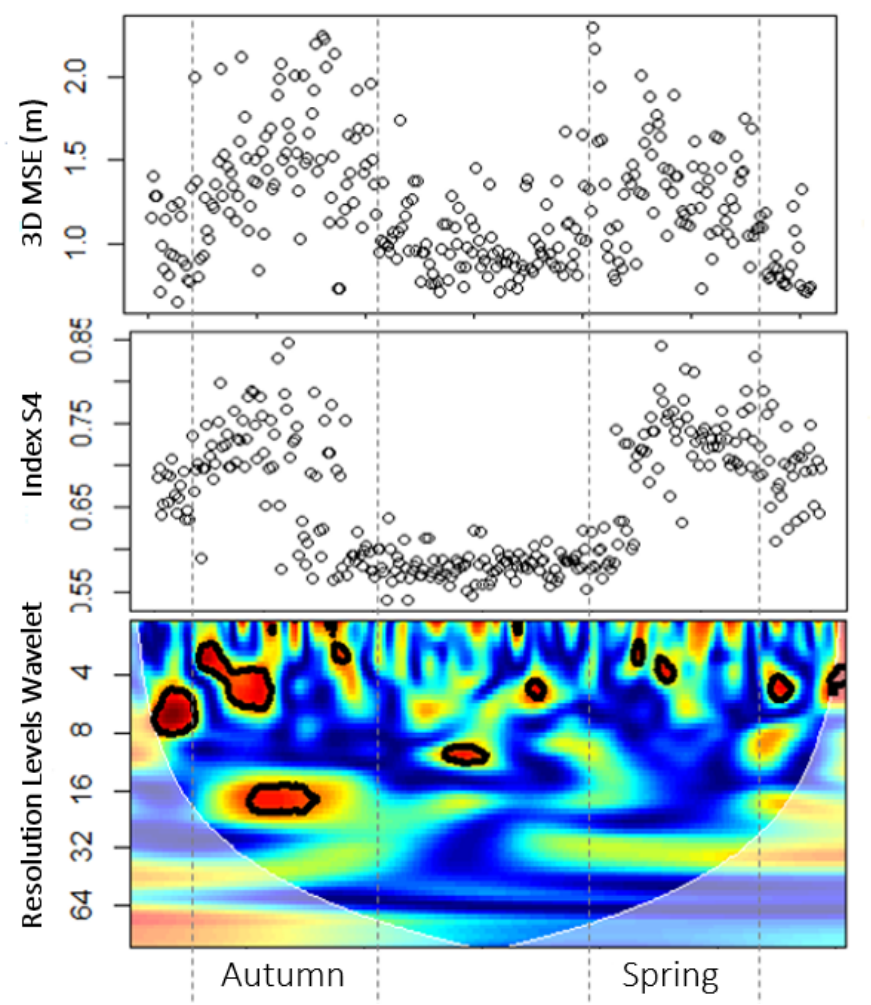

(a)

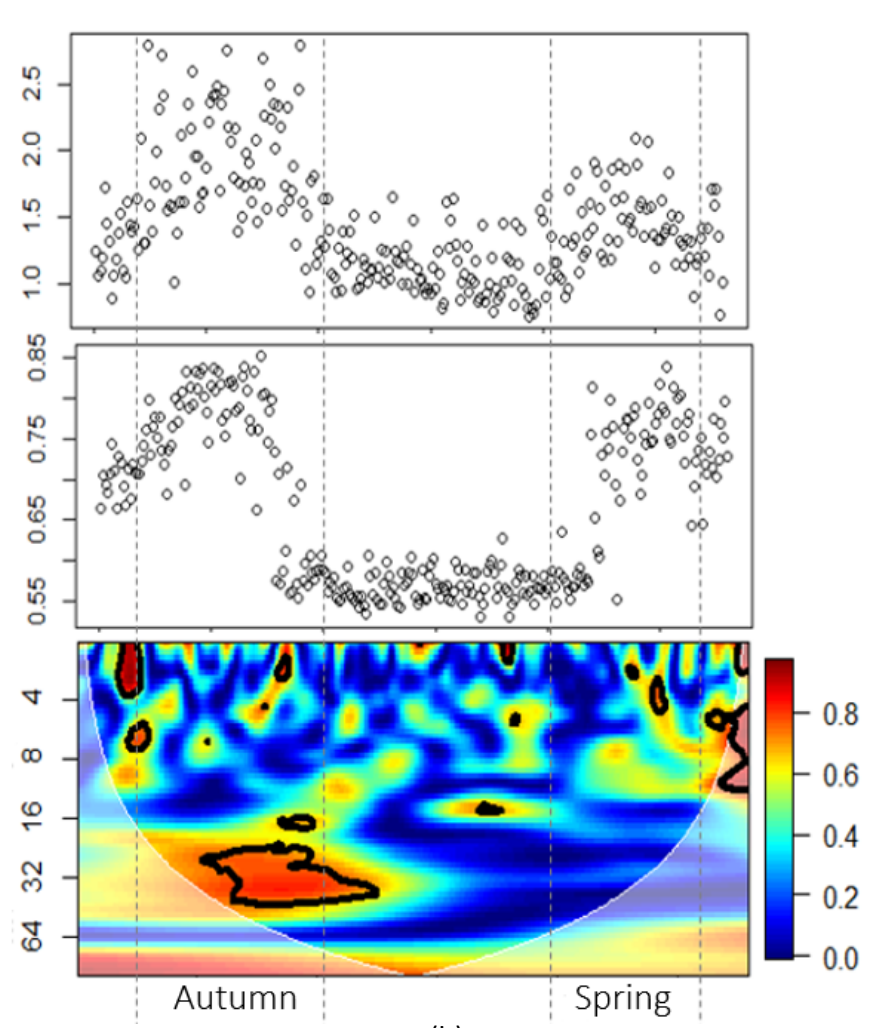

(b)

Figure 9: Wavelet Coherence Color Map from 2012 (a) and 2014 (b) of the PRU2 station 


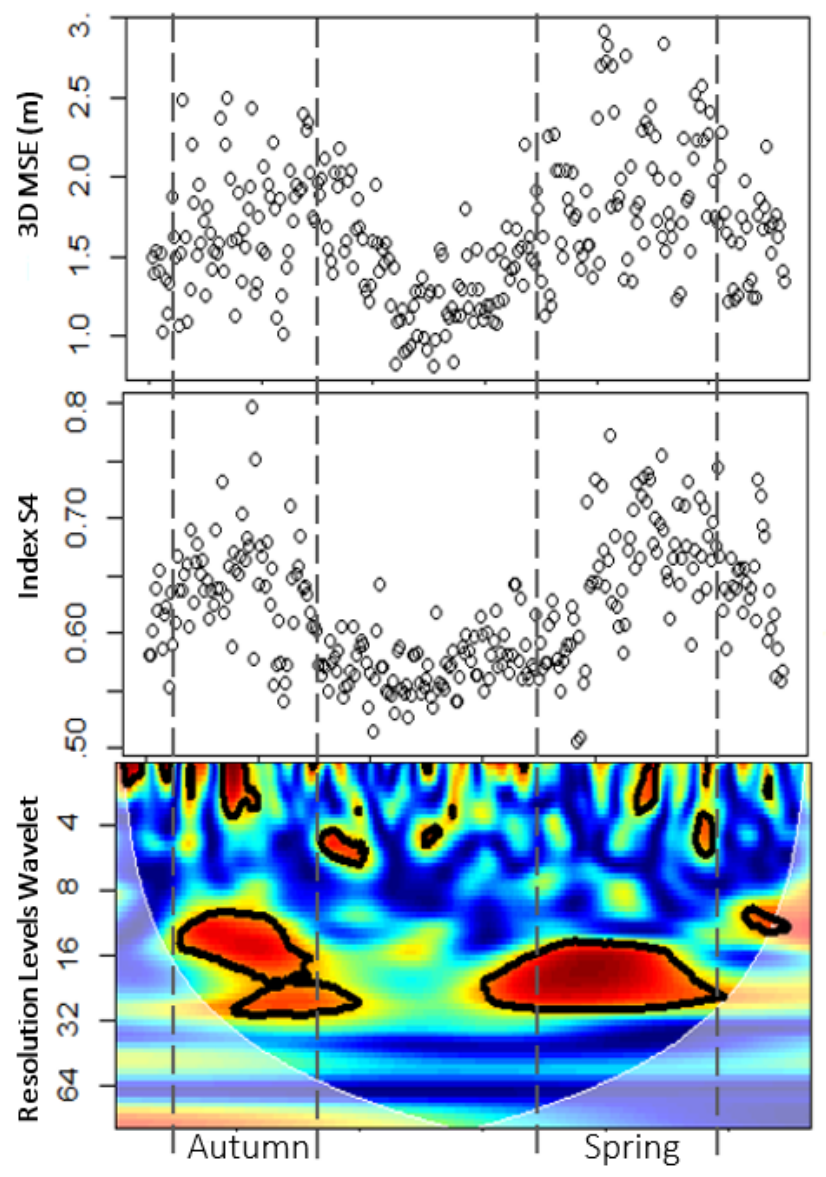

(a)

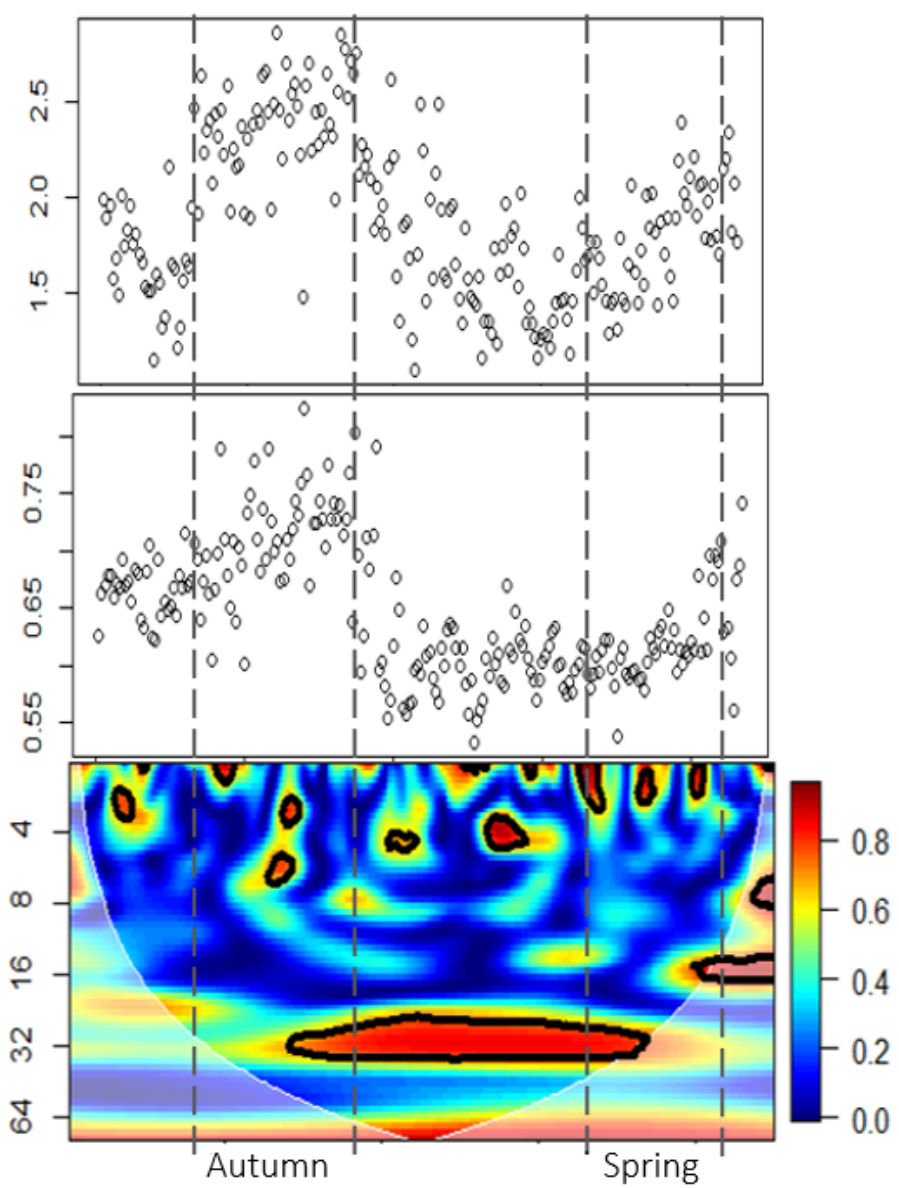

(b)

Figure 10: Wavelet Coherence Color Map from 2012 (a) and 2014 (b) of the PALM station

Through the wavelet coherence color maps presented previously (Figures 9 and 10), patterns and/or information hidden in the scintillation and positioning S4 index series, which could not be identified in the time domain, can be explained in the space-frequency domain. Therefore, it is possible to investigate the effects of ionospheric scintillation on positioning, i.e., to determine the correlation in the space-frequency domain. In this way, the series is decomposed by levels of resolution, related to the $2 \mathrm{j}$ scales, being possible to characterize the series in terms of the scale that concentrates the highest correlation.

Table 2 provides an interpretation of the frequency of decomposition in multiscale by wavelets (Chatfield, 2003; Brassarote, 2014).

Table 2: Interpretation of the frequency of decomposition in multiresolution by wavelets

\begin{tabular}{ccc}
\hline Resolution Level & Frequency Resolution & Daily Data \\
\hline 1 & $2-4$ & 2 to 4 days \\
\hline 2 & $4-8$ & 4 to 8 days \\
\hline 3 & $8-16$ & 8 to 16 days \\
\hline 4 & $16-32$ & 16 to 32 days \\
\hline 5 & $32-64$ & 32 to 64 days \\
\hline 6 & $64-128$ & 64 to 128 days
\end{tabular}

Source: Adapted from Brassarote (2014) 
Note that the 2012 time series of the PRU2 station (Figure 9 (a)) the peak of the autumn equinox shows a correlation of approximately $90 \%$ on the resolution level scale 4 (frequency range $16-32$ ), representing a periodicity of approximately one month. As for the spring equinox, the correlation is approximately $60 \%$ on the resolution level scale 4. Another important point is the seasonal influence of ionospheric scintillation on positioning, highlighted by the high correlation on the resolution level scale 6 ( 2 to 4 months) in the autumn of 2012.

Based on Figure 9 (b) referring to the PRU2 station time series, it is noted that there is a high correlation between the scintillation and mean error positioning series throughout 2014 on the resolution level scale 6 (periodicity from 2 to 4 months), in agreement with the numerical correlation of 0.51 , shown in Table 1, mainly related to the seasonal influence (whose seasons are associated with 3 months). Being that in the period of the spring and autumn equinoxes, presenting a correlation of approximately 60 to $90 \%$, respectively.

With regard to the last one, on the resolution level scale 5 (periodicity from 32 days to 2 months) the correspondence between the series starts at the peak of the autumn equinox and extends to the beginning of the winter solstice, varying between 70 to $80 \%$ of correlation, and the peak of spring is better correlated by the periodicity 8 to 16 days, with approximately $60 \%$.

Regarding the analysis of the effect of ionospheric scintillation on the positioning of the PALM station in 2012 (Figure $10(\mathrm{a})$, it is noted that the correlation is maximum on the resolution level scale 4, reaching a correlation close to $100 \%$, where the equinox and solstice peaks are represented, with a periodicity of 1 month. In addition, the autumn equinox on the resolution level scale 6 has a correlation of 70 to $80 \%$.

Concerning Figure 10 (b) referring to the PALM season time series of 2014, it is noted that there is a high correlation between the scintillation and positioning series throughout the 2014 period on the resolution level scale 6 , in agreement with the numerical correlation of 0.53, shown in Table 1 mainly related to the seasonal influence, being that in the period of the spring and autumn equinoxes, presenting a correlation of approximately 70 to $90 \%$. Furthermore, on the resolution level scale 4, there is a high correlation in the order of 70 to $90 \%$, which starts at the peak of the autumn equinox and extends until the end of the winter solstice. Regarding the peak of spring, it is better correlated by the periodicity of 8 to 16 days with approximately $80 \%$.

Another factor to be highlighted is the spatial influence, since the ionospheric scintillation and consequently the positioning error, are greater in the region of low latitudes, as is the case of the PRU2 station. This fact can be proven by comparing the results obtained in the positioning, as well as the ionospheric scintillation, of the PRU2 and POAL stations at the autumn equinox of 2013. In this case, it is possible to notice that the 3D MSE of the PRU2 station is 2.5 times greater that to the POAL station.

Thus, the POAL station, due to its location, is less vulnerable to ionospheric effects and ionospheric irregularities as shown in Figure 5a. However, Figure 6 shows high $\mathbf{S 4}$ values, being in most cases higher than in the southeastern region, this can be justified by the fact that scintillation data is greater than 0.5 and by weighting the average.

Figure 11 shows the amount of scintillation data (S4>0.5) employed per day. Note that although the PRU2 and PALM stations result in a greater number of daily data used, the POAL station has a high number of S4 values between 0.7 and $1(0.7<S 4<1)$ greater than $1(S 4>1)$, which directly influences the average and the behavior of the scintillation series (Figure $5 a$ ). 

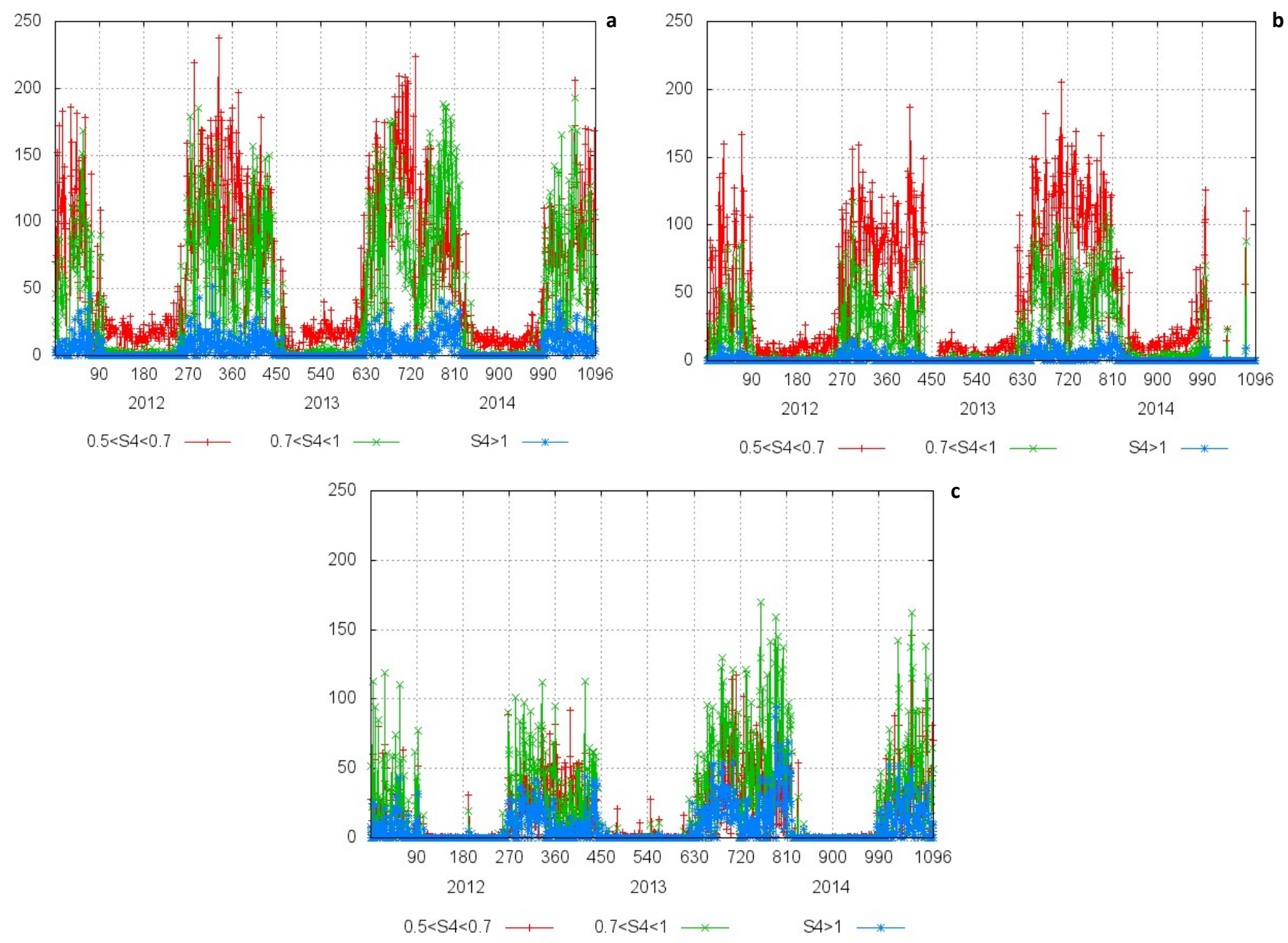

Figure 11: Quantity of scintillation data ( $S 4>0.5$ ) employed per day to calculate the weighted average of PRU2 (a), PALM (b) and POAL (c) stations.

In addition, based on Figures 6 to 8 it is noted that the two annual peaks of the scintillation index S4, referring to the moths of the equinox, are practically of the same magnitude. This uniformity of the peaks can also be justified by the occurrence of sunspots in this period of the series, represented in Figure 2, where the monthly number of spots is shown.

\section{Conclusion}

In this research, an investigation of the effects of the amplitude scintillation on Precise Point Positioning was presented using only the C/A code. The analysis in question considered three years of data in the period of maximum solar activity of cycle 24 , covering the seasonal variation of the ionosphere, especially the summer solstice and equinoxes, when the most intense scintillations are observed.

The investigation of the correlation between the accuracy of the PPP and the occurrence of ionospheric scintillation was based on the statistics of the Mean Squared Error of the positioning and magnitude of the values of the S4 index observed in Brazilian stations. The analysis considered different ionospheric regions, PALM (near the Geomagnetic Equator), PRU2 (low latitudes region and presence of EIA) and POAL (Mid-latitudes region). In this way, based on the MSE time series and the S4 indexes, it was possible to notice the impact of the scintillation on the positioning as a function of the geographical position. At low latitudes, as in the case of the PRU2 station, 
the ionospheric scintillation and consequently the positioning error are greater, reaching 2.5 times greater than the POAL station, at the autumn equinox of 2013.

As a result, there was a correlation of $53 \%$ and $51 \%$ using the Spearman method, for the PALM and PRU2 series, respectively. It is worth mentioning that the maximum correlation of the series of stations occurred at the peak of solar activity in cycle 24, in 2014. As already discussed, this fact directly influences ionized particles, as well as intensifies ionospheric irregularities.

Furthermore, considering the analysis of space-frequency in relation to time by the Wavelet coherence method, it demonstrated an effective technique for the analysis of seasonal variation and for time series with daily data, since it is used in the spring and autumn equinoxes, presenting a correlation of approximately 70 to $90 \%$.

\section{ACKNOWLEDGEMENT}

To FAPESP for funding the first author's scholarship (2014/03858-9), the second author's Regular project (process 2012/19906-7) and the Universal CNPq project (Process 483954/2011-0) of the third author. To the CIGALA and CALIBRA project financed by the European Commission (EC) under the FP7-GALILEO-2009 GSA and FP7GALILEO-2011-GSA-1a, respectively, for providing the data.

\section{AUTHOR'S CONTRIBUTION}

Mayara Caldeira, Carlos Caldeira and Samara Sunny wrote the manuscript and were responsible for preparing and analyzing the data. Daniele Alves and Claudinei de Aguiar provided part of the data and provided technical and scientific support as guidance for the work. All authors contributed to the editing and revision of the manuscript.

\section{REFERENCES}

Abdu, M. A., Kherani, E. A., Batista, I. S., Reinisch, B. W., Sobral, J. H. A. 2014. Equatorial spread F initiation and growth from satellite traces as revealed from conjugate point observations in Brazil. Journal of Geophysical Research: Space Physics, 119(1), pp. 375-383. https://doi.org/10.1002/2013JA019352

Aguiar, C. R. de. 2010. Grade Ionosférica para Aplicações em Posicionamento e Navegação com GNSS. Tese (Doutorado em Ciências Cartográficas) - Universidade Estadual Paulista, Presidente Prudente.

Ahmed, A., Tiwari, R., Strangeways, H. J., Dlay, S., Johnsen, M. G. 2015. Wavelet-based analogous phase scintillation index for high latitudes. Space Weather, 13(8), pp. 503-520. https://doi.org/10.1002/2015SW001183

Alfonsi, L., Wernik, A. W., Materassi, M., Spogli, L. 2017. Modelling ionospheric scintillation under the crest of the equatorial anomaly. Advances in Space Research, 60(8), pp. 1698-1707. https://doi.org/10.1016/j.asr.2017.05.021

Alves, D. B. M., de Souza, E. M., Gouveia, T. A. F. 2020. Correlation between ionospheric scintillation effects and GNSS positioning over Brazil during the last solar maximum (2012-2014). Journal of Atmospheric and Solar-Terrestrial Physics, 197. doi.org/10.1016/j.jastp.2019.03.013

Aquino, M., Monico, J. F. G., Dodson, A. H., Marques, H., De Franceschi, G., Alfonsi, L., Romano, V., Andreotti, M. 2009. Improving the GNSS positioning stochastic model in the presence of ionospheric scintillation. Journal of Geodesy, 83(10), pp. 953-966. https://doi.org/10.1007/s00190-009-0313-6 
Barros, D., Takahashi, H., Wrasse, C. M., Figueiredo, C. A. O. B. 2018. Characteristics of equatorial plasma bubbles observed by TEC map based on ground-based GNSS receivers over South America. Annales Geophysicae, 36(1), pp. 91-100. https://doi.org/10.5194/angeo-36-91-2018

Basu, S., Groves, K. M., Basu, S., Sultan, P. J. 2002. Specification and forecasting of scintillations in communication/ navigation links: Current status and future plans. Journal of Atmospheric and Solar-Terrestrial Physics, 64(16), pp. 1745-1754. doi.org/10.1016/S1364-6826(02)00124-4

Brassarote, G. O. N. 2014. Análise multiescala de séries temporais do efeito da cintilação ionosférica nos sinais de satélite GPS a partir de Wavelets não decimadas. Dissertação (Mestrado em Matemática Aplicada e Computacional) Faculdade de Ciências e Tecnologia, Universidade Estadual Paulista, Presidente Prudente

Brassarote, G. de O. N., Souza, E. M. de, Monico, J. F. G. 2018. S4index: Does it only measure ionospheric scintillation?. GPS Solutions, 22(1). https://doi.org/10.1007/s10291-017-0666-x

Camargo, P. O. 1999. Modelo Regional Da Ionosfera Para Uso Em Posicionamento Com Receptores GPS de Uma Frequência. Tese (Doutorado em Ciências Geodésicas) - Universidade Federal do Paraná, Curitiba.

Cesaroni, C., Spogli, L., Alfonsi, L., De Franceschi, G., Ciraolo, L., Monico, J. F. G., Scotto, C., Romano, V., Aquino, M., Bougard, B. 2015. L-band scintillations and calibrated total electron content gradients over Brazil during the last solar maximum. Journal of Space Weather and Space Climate, 5(A36), pp. 1-10. https://doi.org/10.1051/swsc/2015038

Chatfield, C. 2003. The Analysis of Time Series: An Introduction, Chapman and Hall (6th ed.), London.

Conker, R. S., El-Arini, M. B., Hegarty, C. J., Hsiao, T. 2003. Modeling the effects of ionospheric scintillation on GPS/Satellite-based augmentation system availability. Radio Science, 38(1), pp. 1-23. https://doi. org/10.1029/2000RS002604

Dal Poz, W. R., Camargo, P. de O., de Aguiar, C. R. 2008. Período de mínima atividade solar: Melhora no desempenho do posicionamento relativo. Boletim de Ciências Geodésicas, 14(1), pp. 35-54.

Davies, K. 1990. Ionospheric Radio (Vol. 3, Issue 4). Peter Peregrinus Ltd.

De Paula, E. R., Kantor, I. J., Rezende, L. F. C., Muella, M. T. H., Campos, A. A. N., Smorigo, P. F., Neto, A. C. 2008. Characteristics of the low latitude ionospheric irregularities and their effects over GPS signal. In: Proceedings of Ionospheric Scintillation: Scientific Aspects Space Weather and Services Workshop, Nottingham.

Dubey, S., Wahi, R., Gwal, A. K. 2006. Ionospheric effects on GPS positioning. Advances in Space Research, 38(11), pp. 2478-2484. https://doi.org/10.1016/j.asr.2005.07.030

Fedrizzi, M. 2003. Estudo do efeito de tempestades magnéticas na ionosfera utilizando dados do GPS. Tese (Doutorado em Ciência Espacial/Geofísica Espacial) - Instituto Nacional de Pesquisas Espaciais, São José dos Campos.

Fernández, L. I., Meza, A. . M., Van Zele, M. A. 2013. Wavelet analysis of the ionospheric response at Mid-latitudes during the april 2000 storm using magnetograms and VTEC from GPS. GEOACTA, 37(2), pp. 178-196.

Groves, K. M., Basu, S., Quinn, J. M., Pedersen, T. R., Falinski, K., Brown, A., Silva, R., Ning, P. 2000. A Comparison of GPS Performance in a Scintillation Environment at Ascension Island. In: Proceedings of ION GPS 2000, Institute of Navigation, Salt Lake City, UT, September 2000, pp. 72-679.

Ji, S., Chen, W., Wang, Z., Xu, Y., Weng, D., Wan, J., Fan, Y., Huang, B., Fan, S., Sun, G., Wang, H., Song, D., He, Y. 2013. A study of occurrence characteristics of plasma bubbles over Hong Kong area. Advances in Space Research, 52(11), pp. 1949-1958. https:// doi.org/10.1016/j.asr.2013.08.026

Jiao, Y., Morton, Y. T. 2015. Comparison of the effect of high-latitude and equatorial ionospheric scintillation on GPS signals during the maximum of solar cycle 24. Radio Science, 50(9), pp. 886-903. https://doi. org/10.1002/2015RS005719

Kelley, M. C. 2006. The Earths Ionosphere - Plasma Physics and Electrodynamics. International Geophysics Series, vol 43. San Diego: Academic Press.

Kintner, P. M., Ledvina, B. M., De Paula, E. R. 2007. GPS and ionospheric scintillations. Space Weather, 5(9). https:// doi.org/10.1029/2006SW000260 
Leick, A. 1995. GPS satellite surveying. In John Wiley \& Sons.

Luo, X., Lou, Y., Xiao, Q., Gu, S., Chen, B., Liu, Z. 2018. Investigation of ionospheric scintillation effects on BDS precise point positioning at low-latitude regions. GPS Solutions, 22(63). https://doi.org/10.1007/s10291-018-0728-8

Marques, H. A. S., Monico, J. F. G., Marques, H. A. 2016. Performance of the L2C civil GPS signal under various ionospheric scintillation effects. GPS Solutions, 20(2), pp. 139-149. https://doi.org/10.1007/s10291-015-0472-2

Marques, H. A., Marques, H. A. S., Aquino, M., Veettil, S. V., Monico, J. F. G. 2018. Accuracy assessment of Precise Point Positioning with multi-constellation GNSS data under ionospheric scintillation effects. Journal of Space Weather and Space Climate, 8. https://doi.org/10.1051/swsc/2017043

Materassi, M., Alfonsi, L., Spogli, L., Forte, B. 2020. Scintillation modeling. In S. S. Massimo Materassi, Biagio Forte (Ed.), The Dynamical lonosphere (pp. 277-299). Elsevier. https://doi.org/10.1016/b978-0-12-814782-5.00018-2

Matsuoka, M. (2007). Influência de diferentes condições da ionosfera no posicionamento por ponto com GPS: avaliação na região brasileira. Tese (Doutorado em Ciências Cartográficas) - Programa de Pós-Graduação em Ciências Cartográficas, Faculdade de Ciências e Tecnologia, Universidade Estadual Paulista, Presidente Prudente.

Matsuoka, M. T., Camargo, P. de O. 2007. Correção ionosférica utilizando os Mapas Globais do TEC do IGS: Avaliação no posicionamento por ponto na região brasileira. Boletim de Ciências Geodésicas, 13(2), pp. 253-270.

McNamara, L. F. 1991. The ionosphere: communications, surveillance, and direction finding. Flórida: Krieger Publishing Company.

Mendonça, M. 2013. Investigação da cintilação ionosférica no Brasil e seus efeitos no posicionamento por GNSS. Dissertação (Mestrado) - Programa de Pós-Graduação em Ciências Cartográficas, Faculdade de Ciências e Tecnologia da UNESP, Presidente Prudente.

Moldwin, M. 2008. An Introduction to Space Weather. New York: Cambridge Press.

Monico, J. F. G. 2008. Posicionamento Pelo G.N.S.S: Descrição, Fundamentos e Aplicações (2a ed). Editora UNESP.

Montenbruck, O., Steigenberger, P., Prange, L., Deng, Z., Zhao, Q., Perosanz, F., Romero, I., Noll, C., Stürze, A., Weber, G., Schmid, R., MacLeod, K., Schaer, S. 2017. The Multi-GNSS Experiment (MGEX) of the International GNSS Service (IGS) - Achievements, prospects and challenges. Advances in Space Research, 59(7), pp. 1671-1697. https://doi. org/10.1016/j.asr.2017.01.011

Moraes, A. de O., Vani, B. C., Costa, E., Abdu, M. A., de Paula, E. R., Sousasantos, J., Monico, J. F. G., Forte, B., Negreti, P. M. de S., Shimabukuro, M. H. 2018. GPS availability and positioning issues when the signal paths are aligned with ionospheric plasma bubbles. GPS Solutions, 22(4). https://doi.org/10.1007/s10291-018-0760-8

Moreno, B., Radicella, S., de Lacy, M. C., Herraiz, M., Rodriguez-Caderot, G. 2011. On the effects of the ionospheric disturbances on precise point positioning at equatorial latitudes. GPS Solutions, 15(4), pp. 381-390. https://doi. org/10.1007/s10291-010-0197-1

Muella, M. T. A. H., de Paula, E. R., Monteiro, A. A. 2013. Ionospheric Scintillation and Dynamics of Fresnel-Scale Irregularities in the Inner Region of the Equatorial Ionization Anomaly. Surveys in Geophysics, 34(2), pp. 233-251. https://doi.org/10.1007/s10712-012-9212-0

NASA, National Aeronautics and Space Administration, Available at: < https://solarscience.msfc.nasa.gov/images/ ssn_predict_l.gif >. [Acessed 30 Janyary, 2019]

Oliveira, A. B. V. 2003. Uso do GPS para o estudo da Anomalia Equatorial. Dissertação (Mestrado) - Programa de Pós Graduação de Engenharia Eletrônica e Computação, Instituto Tecnológico de Aeronáutica, São José dos Campos-SP.

Park, J., Veettil, S. V., Aquino, M., Yang, L., Cesaroni, C. 2017. Mitigation of lonospheric Effects on GNSS Positioning at Low Latitudes. Navigation, Journal of the Institute of Navigation, 64(1), pp. 67-74. https://doi.org/10.1002/navi.177

Pereira, V. A. S., Pugliesi, E. A., Flores, E. F., Camargo, P. de O. 2018. Krigagem ordinária e visualização de incertezas aplicadas no monitoramento de irregularidades ionosféricas no Brasil. Revista Brasileira de Cartografia, 70(3), pp. 967-996. https://doi.org/10.14393/rbcv70n3-45708 
Pereira, V. A. S., Camargo, P. de O. 2017. Brazilian active GNSS networks as systems for monitoring the ionosphere. GPS Solutions, 21(3), pp. 1013-1025. https://doi.org/10.1007/s10291-016-0589-y

Ram, S. T., Su, S. Y., Liu, C. H. 2009. FORMOSAT-3/COSMIC observations of seasonal and longitudinal variations of equatorial ionization anomaly and its interhemispheric asymmetry during the solar minimum period. Journal of Geophysical Research: Space Physics, 114(6). https://doi.org/10.1029/2008JA013880

Rishbeth, H., Garriott, O. K. 1969. Introduction to ionospheric physics (1st ed., Vol. 47). Academic Press. https://doi. org/10.1016/0021-9169(71)90209-1

Ruviaro, J. S., Matsuoka, M. T., Camargo, P. D. O. 2012. Análise Global dos Efeitos Provocados pela Explosão Solar de 28 de Outubro de 2003 no TEC e no Posicionamento Por Ponto. Revista Brasileira de Cartografia, 65(1), pp. 211-226.

Sahai, Y., Fagundes, P. R., Bittencourt, J. A. 2000. Transequatorial F-region ionospheric plasma bubbles: solar cycle effects. Journal of Atmospheric and Solar-Terrestrial Physics, 62(15), pp. 1377-1383. https://doi.org/10.1016/s13646826(00)00179-6

Salomoni, C. S., Matsuoka, M. T., de Souza, S. F., Camargo, P. de O. 2009. Análise e comparação do comportamento da ionosfera e do posicionamento por ponto em períodos de alta e baixa atividade solar. Boletim de Ciências Geodésicas, 15(3), pp. 333-351.

Seeber, G. 2003. Satellite Geodesy: Foundations, Methods, and Applications. Walter de Gruyter.

Skone, S. 2000. Wide Area lonosphere Modeling at Low Latitudes - Specifications and Limitations. In: 13TH International Technical Meeting of Satellite Division of the Institute of Navigation - ION GPS.

Skone, S., Knudsen, K., De Jong, M. 2001. Limitations in GPS reciever tracking performance under ionospheric scintillation conditions. Physics and Chemistry of the Earth, Part A: Solid Earth and Geodesy, 26(6-8), pp. 613-621. https://doi.org/10.1016/S1464-1895(01)00110-7

Skone, S., Shrestha, S. M. 2002. Limitations in DGPS positioning accuracies at low latitudes during solar maximum. Geophysical Research Letters, 29(10), pp. 81-1 - 81-84. https://doi.org/10.1029/2001gl013854

Souza, J. S., Alves, D. B. M., Vani, B. C. 2015. Estudo do comportamento da Cintilação lonosférica em diferentes regiões brasileiras e seu impacto no posicionamento GNSS. Revista Brasileira de Cartografia, 67(1), pp. 97-109.

Sreeja, V., Aquino, M., Elmas, Z. G., Forte, B. 2012. Correlation analysis between ionospheric scintillation levels and receiver tracking performance. Space Weather, 10(6). https://doi.org/10.1029/2012SW000769

Tiwari, R., Skone, S., Tiwari, S., Strangeways, H. J. 2011. WBMod assisted PLL GPS software receiver for mitigating scintillation affect in high latitude region. In: 30th URSI General Assembly and Scientific Symposium, URSIGASS, Istanbul, Turkey, pp. 1-4. https://doi.org/10.1109/URSIGASS.2011.6050861

UNAVCO. (2014). Teqc Tutorial: Basics of Teqc Use and Teqc Products. Available at: < https://www.unavco.org/ software/data-processing/teqc/doc/UNAVCO_Teqc_Tutorial.pdf>. [Acessed 30 July, 2019]

Vani, B. C., Shimabukuro, M. H., Monico, J. F. G. 2017. Visual exploration and analysis of ionospheric scintillation monitoring data: The ISMR Query Tool. Computers and Geosciences, 104, pp. 125-134. https://doi.org/10.1016/j. cageo.2016.08.022

Vani, B. C.; Forte, B.; Monico, J. F. G.; Skone, S.; Shimabukuro, M. H.; Moraes, A. De O.; Portella, I. P.; Marques, H. A. 2019. A Novel Approach to Improve GNSS Precise Point Positioning During Strong lonospheric Scintillation: Theory and Demonstration. IEEE Transactions on Vehicular Technology, 68(5), pp. 4391-4403. DOI: https://doi.org/10.1109/ TVT.2019.2903988.

Veettil, S. V., Aquino, M., Marques, H. A., Moraes, A. 2020. Mitigation of ionospheric scintillation effects on GNSS precise point positioning (PPP) at low latitudes. Journal of Geodesy, 94(2). https://doi.org/10.1007/s00190-020-01345-z

Webster, L. 1993. A Regional Model for Prediction of lonospheric Delay for Single Frequency Users of the Global Positioning System. M.Sc.E Thesis - Department of Surveying Engineering, University of New Brunswick, New Brunswick, Canada. 


\section{Erratum}

On the page 1 , where it reads:

"Claudinei Rodrigues de Aguiar Caldeira"

Should read:

"Claudinei Rodrigues de Aguiar"

Still on the page 1, in "How to cite this article", where it reads:

CALDEIRA, M. C. O.; CALDEIRA, C. R. T.; CEREJA S. S. A.; ALVES, D. B. M.; CALDEIRA, C. R. A. Evaluation of the GNSS positioning performance under influence of the ionospheric scintillation. Bulletin of Geodetic Sciences. 26(3): e2020014, 2020.

Should read:

CALDEIRA, M. C. O.; CALDEIRA, C. R. T.; CEREJA S. S. A.; ALVES, D. B. M.; AGUIAR, C. R. Evaluation of the GNSS positioning performance under influence of the ionospheric scintillation. Bulletin of Geodetic Sciences. 26(3): e2020014, 2020. 